\title{
Cholestatische Lebererkrankungen
}

Primär biliäre Zirrhose und primär sklerosierende Cholangitis

\section{Eine und nur eine Antwort ist jeweils richtig!}

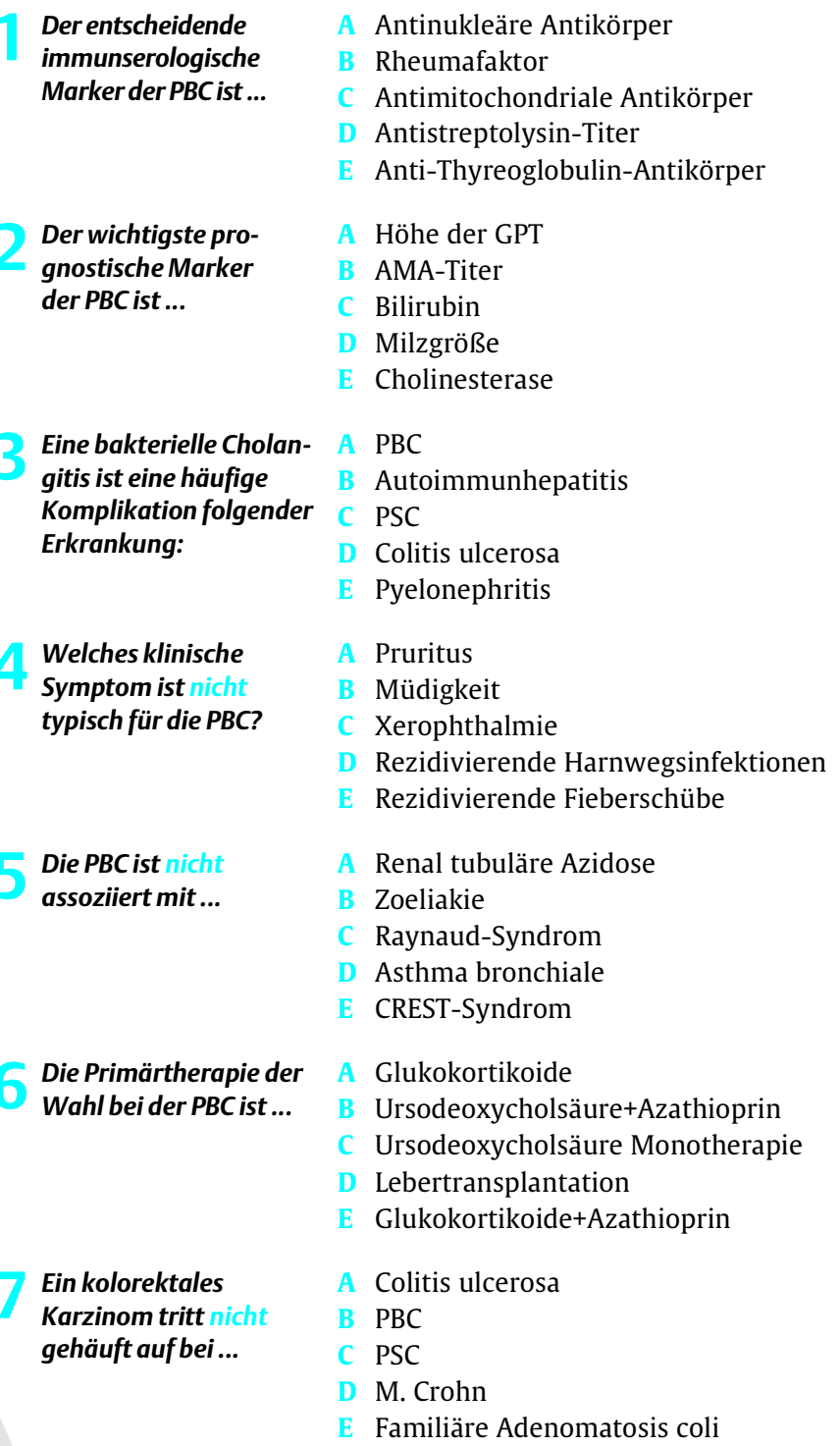




\begin{tabular}{|c|c|c|}
\hline 8 & $\begin{array}{l}\text { pANCA ist ein typischer } \\
\text { SerologischerParameter } \\
\text { der... }\end{array}$ & $\begin{array}{l}\text { A PBC } \\
\text { B AIC } \\
\text { C PSC } \\
\text { D Chronische Hepatitis C } \\
\text { E Autoimmunhepatitis }\end{array}$ \\
\hline & $\begin{array}{l}\text { Der typische Patient mit } \\
\text { PBC ist ... }\end{array}$ & $\begin{array}{l}\text { A Männlich, über } 50 \text { Jahre } \\
\text { B Männlich, } 20 \text { - } 50 \text { Jahre } \\
\text { C Weiblich, unter } 20 \text { Jahre } \\
\text { D Weiblich, } 40 \text { - } 60 \text { Jahre } \\
\text { E Männlich oder weiblich, über } 70 \text { Jahre }\end{array}$ \\
\hline & $\begin{array}{l}\text { Die wichtigste Ver- } \\
\text { dachtsdiagnose bei } \\
\text { einem Patienten mit } \\
\text { Colitis ulcerosa und } \\
\text { eröhter alkalischer } \\
\text { Phosphatase ist... }\end{array}$ & $\begin{array}{ll}\text { A } & \text { PSC } \\
\text { B } & \text { AIH } \\
\text { C } & \text { Hepatitis C } \\
\text { D } & \text { Medikamentös toxische Leberschädigung } \\
\text { E } & \text { PBC }\end{array}$ \\
\hline & $\begin{array}{l}\text { Welche Konstellation } \\
\text { spricht am ehesten für } \\
\text { das Vorliegen einer PSC? }\end{array}$ & $\begin{array}{l}\text { A erhöhte Transaminasen, niedriger Quick-Wert, sonographisch homogen } \\
\text { verdichtete Leber } \\
\text { B AP-Erhöhung, positiver AMA-Titer, sonographisch inhomogene Leber } \\
\text { C Nachweis von p-ANCA, AP-Erhöhung, perlschnurartiger Strikturen der } \\
\text { Gallenwege in der ERCP } \\
\text { D AP-Erhöhung, Bilirubin-Erhöhung, Erweiterung der intra- und } \\
\text { extrahepatischen Gallenwege in der ERCP } \\
\text { E AFP-Erhöhung, Ikterus, sonographisch inhomogene Leber }\end{array}$ \\
\hline
\end{tabular}

\section{Teilnahmebedingungen}

Für diese Fortbildungseinheit erhalten Sie einen Fortbildungspunkt im Rahmen des freiwilligen Fortbildungszertifikates. Hierfür

- müssen 9 der 11 Quiz-Fragen richtig beantwortet sein (bestanden hat auch, wer nicht weniger Fragen richtig beantwortet hat als der Durchschnitt aller Teilnehmer).

- müssen Seite 1 und Seite 2 des Evaluationsbogens vollständig ausgefüllt sein. Unvollständig ausgefüllte Bögen können nicht berücksichtigt werden!

- muss eine CME-Wertmarke im Feld D (Evaluationsbogen) aufgeklebt oder Ihre DMW-Abonnement-Nummer eingetragen sein.

\section{Datenschutz}

Ihre Daten werden ausschließlich für die Bearbeitung dieser Fortbildungseinheit verwendet. Es erfolgt keine Speicherung der Ergebnisse über die für die Bearbeitung der Fortbildungseinheit notwendige Zeit hinaus. Die Daten werden nach Versand der Testate anonymisiert. Namens- und Adressangaben dienen nur dem Versand der Testate. Die Angaben zur Person dienen nur statistischen Zwecken und werden von den Adressangaben anonymisiert verarbeitet.

\section{Einsendeschluss ist der 6.11.2002}

(Datum des Poststempels). Die Zertifikate werden ab dem 13.11.2002 auf dem Postweg versandt. Von telefonischen Anfragen bitten wir abzusehen. Die richtige Auflösung des Quiz wird in der DIMW Nr. 46/2002 (erscheint am 15.11.2002) veröffentlicht. 